PESQUISA

\title{
Características de uvas recobertas com filme plástico de diferentes espessuras e armazenadas em ambiente com e sem refrigeração
}

SCOPEL, Wanessa; ${ }^{\star}$ BARBOSA, Julierme Zimmer; ${ }^{\star \star}$ HOFFMANN, Daniela ${ }^{\star \star \star}$

Resumo

Objetivou-se com esta pesquisa avaliar características físicas, físico-químicas e químicas de uvas quando recobertas com filme plástico de diferentes espessuras e armazenadas em ambiente com e sem refrigeração. As uvas da variedade Francesa foram obtidas em um pomar doméstico localizado próximo à Universidade do Oeste de Santa Catarina, no município de São José do Cedro. As frutas foram colhidas manualmente, pela manhã, acondicionadas em recipiente plástico e transportadas ao Laboratório Multiuso do Curso de Agronomia. Selecionaram-se as frutas sem danos aparentes, maduras, com tamanho e aparência comercial, as quais foram submetidas ao processo de desinfestação, secadas em temperatura ambiente, acondicionadas em bandeja, recobertas com filme PVC e armazenadas. Os tratamentos corresponderam a quatro diferentes espessuras de PVC, duas temperaturas de armazenamento e duas épocas de avaliação. O delineamento experimental foi completamente casualizado em esquema fatorial com três repetições. As avaliações físicas, físico-químicas e químicas foram: perda de massa, pH, Sólidos Solúveis Totais (SST), Acidez Total Titulável (ATT) e a relação SST/ ATT. Os dados obtidos foram submetidos à análise de variância e as médias comparadas pelo teste de Tukey, a 5\% de probabilidade. Para a descrição das variáveis em virtude das espessuras de PVC foram feitas análises de regressão e os modelos que melhor se ajustaram foram selecionados. Concluiu-se que a utilização de embalagens de PVC reduz a perda de massa de uvas e, associada ao uso de refrigeração a $4^{\circ} \mathrm{C}$, mantém a qualidade das frutas por até 12 dias.

Palavras-chave: Uva. Ambiente refrigerado. Espessura. PVC.

\section{Characteristics of grape recovered with plastic films of different thickness and stored in environment with and without refrigeration}

Abstract

The aim of this study was to evaluate physical, physical-chemical and chemical grapes when covered with plastic film of different thickness and stored in an environment with and without cooling. The grapes were obtained in a French household orchard located near the University of West of Santa Catarina, in the municipality of São José do Cedro. The fruits were harvested manually in the morning, packed in plastic container and transported to the Multipurpose Laboratory course in Agronomy. Fruits were selected without any, mature size and trade dress, which were submitted to the process of disinfection, dried at room temperature, packed in tray and covered with PVC film and stored. The treatments consisted of four different thicknesses of PVC, two storage temperatures and two growth periods. The experimental design was completely randomized factorial with three replications. The evaluations, physical-chemical and chemical were: weight loss, $p H$, total soluble solids (TSS), titratable acidity (TTA) and TSS/TTA. The data were subjected to ANOVA and means compared by Tukey test at $5 \%$ probability. For the description of variables depending on the thickness of PVC, were analyzed and regression models that best fit were selected. The use of $P V C$ packaging reduces the weight loss of grapes, and associated with the use of refrigeration at $4{ }^{\circ} \mathrm{C}$ maintains the quality of fruit for up to 12 days.

Keywords: Grape. Cool environment. Thickness. PVC.

*Universidade do Oeste de Santa Catarina; wanessa_scopel@yahoo.com.br

${ }^{\star \star}$ Universidade de Santa Catarina; juliermezimmer@yahoo.com.br

${ }^{\star \star \star}$ Universidade do Oeste de Santa Catarina; danihoffmann@unoescsmo.edu.br

Evidência, Joaçaba v. 8 n. 1-2, p. 43-56, janeiro/dezembro 2008 
A viticultura como atividade agroeconômica é difundida por todo o mundo (EMPRESA DE PESQUISA AGROPECUÁRIA E EXTENSÃO RURAL, 2005, p. 29). A produção de uva (Vitis vinifera) em 82,58 mil hectares de área plantada no Brasil somou 1,34 milhão de toneladas em 2009. Esse valor foi 4\% menor do que em 2008 devido à crise mundial que refletiu na produção de uvas de mesa e provocou o abandono dos vinhedos pelos produtores, além disso, fatores climáticos desfavoráveis resultaram em menor produção. No Estado de Santa Catarina são produzidas cerca de 67,5 mil toneladas em 4,9 mil hectares de área cultivada (INSTITUTO BRASILEIRO DE VINHO, 2010). Essa produção é necessária para atender à crescente demanda de consumo in natura ou na forma de vinhos, sucos e doces.

Conforme a Tabela 1 nota-se que o consumo per capita de uva e seus derivados aumentou do ano de 2000 para 2005, destacando que nesse intervalo de tempo o consumidor brasileiro elevou, aproximadamente, $52 \%$ o seu consumo de uva de mesa.

Tabela 1: Consumo per capita de vinhos, sucos e uvas no Brasil 2000/2005

\begin{tabular}{lcccccc}
\hline Produtos/anos & $\mathbf{2 0 0 0}$ & $\mathbf{2 0 0 1}$ & $\mathbf{2 0 0 2}$ & $\mathbf{2 0 0 3}$ & $\mathbf{2 0 0 4}$ & $\mathbf{2 0 0 5}$ \\
\hline Vinho (L) & 1,89 & 1,81 & 1,71 & 1,68 & 1,76 & 2,01 \\
Suco de uva (L) & 0,33 & 0,35 & 0,34 & 0,39 & 0,37 & 0,54 \\
Uvas de mesa (Kg) & 2,32 & 3,42 & 3,42 & 3,39 & 3,52 & 3,54 \\
Uvas secas (Kg) & 0,09 & 0,10 & 0,08 & 0,08 & 0,09 & 0,09 \\
\hline
\end{tabular}

Fonte: Mello (2005, p. 4).

Ao inserir as frutas em sua alimentação os consumidores buscam os possíveis benefícios nutracêuticos destas. Diversos efeitos positivos à saúde têm sido atribuídos às substâncias encontradas em alta quantidade nas frutas e hortaliças, denominadas de compostos fenólicos (FERRARI; TORRES, 2002, p. 253). A uva é considerada uma das maiores fontes desses compostos, com destaque para aquelas de coloração mais escura, uma vez que essa característica é correlacionada com uma maior capacidade antioxidante (ABE et al., 2007, p. 398). Segundo Hung et al. (2000, p. 554), outra substância de importância comprovada encontrada na uva é o resveratrol, um potente inibidor de radicais livres com atividade específica na prevenção de doenças cardiovasculares, como a arritmia cardíaca, que é uma causa muito frequente de mortalidade.

A composição química da uva varia bastante em razão do clima, solo, variedade, cultivo e outros fatores, porém, geralmente contém em maiores quantidades açúcares, minerais e vitaminas importantes. Por apresentar alta quantidade de açúcar (glicose e frutose) é considerado um alimento Evidência, Joaçaba v. 8 n. 1-2, p. 43-56, janeiro/dezembro 2008 
Características de uvas recobertas com filme plástico de diferentes espessuras...

energético. A acidez do suco é em consequência da presença dos ácidos tartárico, málico e cítrico. Esses ácidos orgânicos lhe conferem um pH baixo, garantindo um equilíbrio entre os gostos doce e ácido (RIZZON; MIELE, 1995, p. 130 apud PINHEIRO et al., 2009, p. 374).

Devido à fragilidade, a uva é considerada um produto altamente perecível, com perdas na fase de pós-colheita estimadas em 27\% da produção total; estas se devem a diversas causas (BENATO, 1998, p. 98). As principais causas de danos aos alimentos na cadeia de comercialização são apresentadas no Esquema 1.

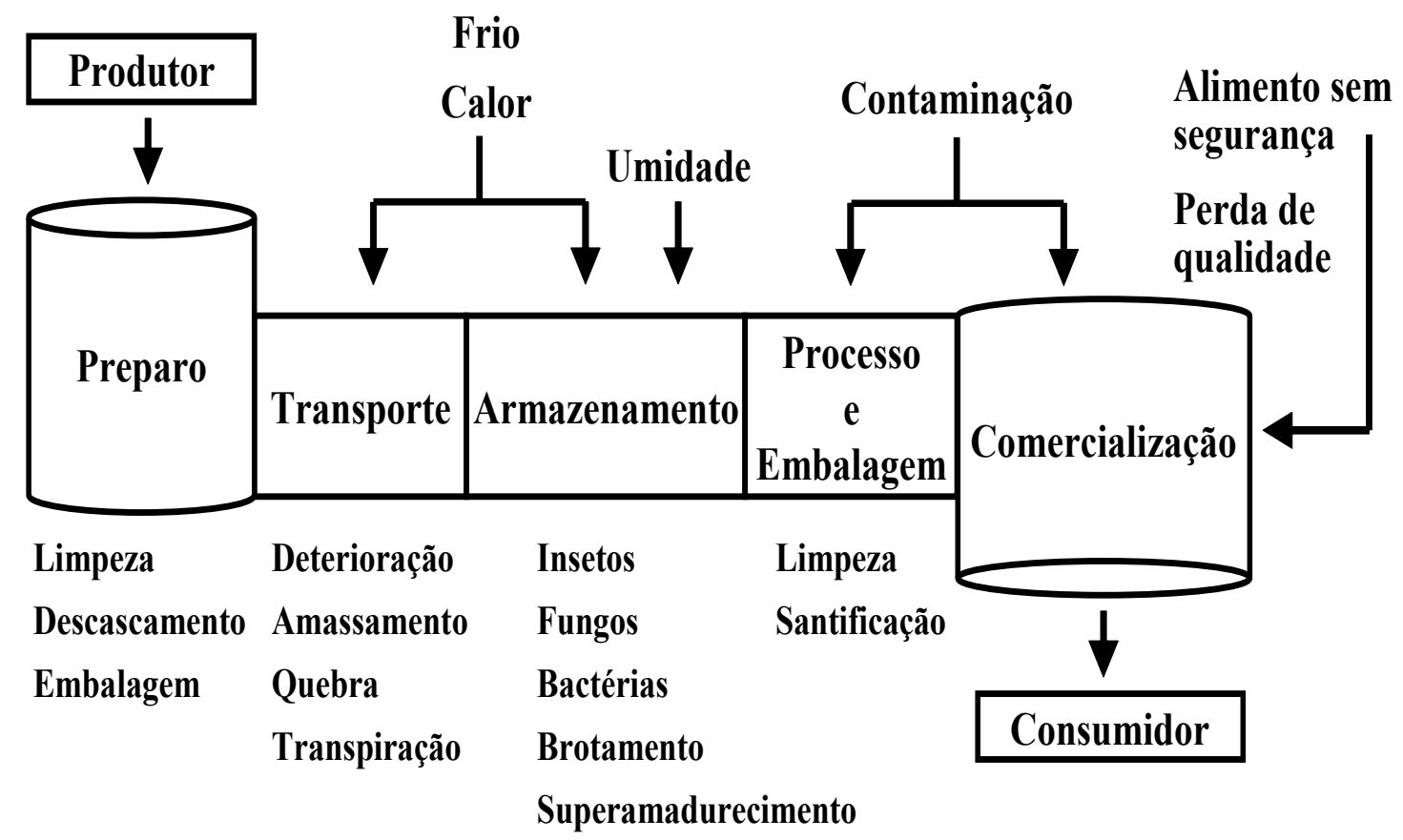

Esquema 1: Principais causas de danos aos alimentos na cadeia de comercialização Fonte: adaptado de Booth (1980) por Chitarra e Chitarra (2005, p. 165).

De acordo com Chitarra e Chitarra (2005, p. 165), as perdas dos produtos agrícolas são resultantes de condições inadequadas em toda a cadeia de comercialização, desde o manuseio e preparo ainda na unidade de produção, passando pelos setores de transporte, armazenagem e embalagem até o destino final, o consumidor. A interação entre fatores biológicos, microbiológicos, químicos, físicos, mecânicos e fisiológicos com o inadequado tratamento dos produtos vegetais por aqueles que os manuseiam, afetam diretamente a qualidade e a segurança dos alimentos.

Por ser um fruto não climatérico, a uva apresenta baixas taxas de respiração e uma vida de prateleira relativamente longa, quando armazenada sob condições apropriadas de temperatura $(0$ a 2 ${ }^{\circ} \mathrm{C}$ ) e umidade relativa (90\% a 95\%) (CHITARRA; CHITARRA, 2005, p. 80). Uma das principais causas de redução da vida útil da uva ocorre em razão da perda de massa, que torna a casca enrugada e sem brilho, causa o ressecamento do engaço e do pedicelo e as bagas perdem a turgidez, tornando o produto impróprio para comercialização, no caso do consumo in natura (YAMASHITA et al., 2000, 
p. 111). Analisando o mercado brasileiro de frutas de mesa, é possível perceber uma exigência cada vez maior dos consumidores nacionais por uvas de melhor qualidade, não somente em relação ao aspecto visual, mas, também, em relação ao sabor, aroma e consistência (LULU; CASTRO; PEDRO JUNIOR, 2005, p. 422).

A redução da perda de massa pode ser minimizada com a utilização de um sistema de umidificação da câmara de armazenagem, entretanto, o custo fixo e operacional deste processo tende a aumentar, além de permitir maior incidência de podridão causada por fungos, caso a umidade seja maior do que 95\% (YAMASHITA et al., 2000, p. 111).

A maioria dos processos que ocorrem nos tecidos vegetais está associada a reações enzimáticas, cuja velocidade depende da temperatura. De acordo com Pataro e Silveira Júnior (2004, p. 158), a temperatura é o fator que mais afeta a longevidade da uva após a colheita, sendo o resfriamento e a conservação à baixa temperatura de suma importância para frutas e hortaliças, já que a sua comercialização em ambientes de venda não refrigerados acarreta uma diminuição na vida útil do alimento, modificando as características físicas, visuais e até nutricionais. Chitarra e Chitarra (2005, p. 340) citam que a utilização de temperaturas baixas regula as taxas dos processos fisiológicos e bioquímicos associados com a redução da respiração, havendo decréscimo na perda de aroma, sabor, textura, cor e demais atributos de qualidade dos produtos vegetais. Assim, o armazenamento refrigerado prolonga o período de comercialização da fruta fresca, porém, não evita alterações físicoquímicas, que depreciam sua qualidade (CARVALHO; MANICA, 1994, p. 682).

Chitarra e Chitarra (2005, p. 340) citam que o uso de filmes plásticos alteram a atmosfera ambiental (intraembalagem), pois quando um vegetal é acondicionado e fechado dentro de uma embalagem plástica, a concentração de $\mathrm{O}_{2}$ no espaço livre da embalagem tende a decrescer e a concentração de $\mathrm{CO}_{2}$ se eleva, devido à respiração (processo que consome $\mathrm{O}_{2}$ e libera $\mathrm{CO}_{2}$ ), estabelecendo-se uma atmosfera de equilíbrio em razão de um estado de equilíbrio entre a difusão de gases através da embalagem e a respiração do produto. Antes do fechamento a embalagem pode conter ar, sofrer evacuação ou receber a injeção de uma atmosfera otimizada para conservação do vegetal. Todos esses casos possuem tendência de atingir a atmosfera de equilíbrio na qual a durabilidade do produto é maximizada (SARANTÓUPOLOS, 1997, p. 3).

De acordo com Sarantóupolos (1997, p. 3), quando os vegetais são fechados dentro de embalagens plásticas com ar, durante a estocagem a modificação da atmosfera é passiva, ou seja, ocorre em consequência da respiração do produto e da permeação dos gases pela embalagem. Um filme plástico específico tem sua aplicação limitada na preservação de vegetais, em razão da sua taxa de permeabilidade a gases específica. Assim, filmes com diferentes barreiras são necessários para preservar o frescor de frutas e hortaliças com diferentes taxas de respiração. Entre os filmes atualmente indicados para esse propósito está o Policloreto de Vinila (PVC); de acordo com Zaicovski et al. (2006, p. 446) também tem o objetivo de manter as frutas firmes e reduzir seu deslocamento interno.

Evidência, Joaçaba v. 8 n. 1-2, p. 43-56, janeiro/dezembro 2008 
Características de uvas recobertas com filme plástico de diferentes espessuras...

Todavia, o uso de filmes com permeabilidade a gases insuficiente, em que o nível de $\mathrm{O}_{2}$ tornase muito baixo, promove respiração anaeróbica; excesso de $\mathrm{CO}_{2}$ pode causar desordem fisiológica; permeabilidade excessiva ao vapor d'água causa enrugamento do produto, ao passo que a redução excessiva pode embaçar a embalagem e auxiliar no crescimento de microrganismos (CHITARRA; CHITARRA, 2005, p. 337).

Conforme Araújo et al. (2009, p. 868), aliando-se a praticidade, o custo relativamente baixo e a alta eficiência de filmes plásticos à base de polietileno ou policloreto de vinila com o armazenamento refrigerado, tem-se a possibilidade de associações sinérgicas que venham a contribuir de forma a evitar perdas e possibilitando que, mediante a modificação da atmosfera, frutos perecíveis tenham a sua vida pós-colheita prolongada.

Diante do exposto, o objetivo desta pesquisa foi avaliar características físicas, físico-químicas e químicas de uvas quando recobertas com filme plástico de diferentes espessuras e armazenadas em ambiente com e sem refrigeração.

\section{DESENVOLVIMENTO}

\subsection{MATERIAIS E MÉTODOS}

Obtiveram-se as uvas da variedade Francesa utilizadas neste trabalho em um pomar doméstico localizado próximo à Universidade do Oeste de Santa Catarina, no município de São José do Cedro. As frutas foram colhidas manualmente, pela manhã, acondicionadas em recipiente plástico com capacidade para 25 L e transportadas ao Laboratório Multiuso do Curso de Agronomia.

Para melhor uniformização das parcelas, selecionaram-se as frutas sem danos aparentes, maduras e com tamanho e aparência comercial, as quais foram submetidas ao processo de desinfestação em água clorada (50 $\mathrm{mL} \mathrm{L}^{-1}$ de hipoclorito de sódio) durante 30 minutos, secadas em temperatura ambiente, acondicionadas em bandeja de poliestireno expandido, recobertas com filme de cloreto de polivinila (PVC) esticável e autoaderente e, armazenadas.

Os tratamentos corresponderam a quatro diferentes espessuras de PVC (sem embalagem, 8, 16 e $24 \mu \mathrm{m}$ ), duas temperaturas de armazenamento $\left(4\right.$ e $25^{\circ} \mathrm{C}$ ) e duas épocas de avaliação (6 e 12 dias a partir da instalação do experimento). O delineamento experimental foi completamente casualizado em esquema fatorial com três repetições, totalizando 48 unidades experimentais.

As avaliações físicas, físico-químicas e químicas foram: perda de massa, pH, Sólidos Solúveis Totais (SST), Acidez Total Titulável (ATT) e a relação SST/ATT. Calculou-se a perda de massa por meio de pesagem no dia da instalação do experimento, em balança semianalítica com precisão de 0,01 $\mathrm{g}$, e a cada tempo de retirada de amostras foram pesadas novamente. Os resultados foram expressos em \%. Mediu-se o pH diretamente no suco, logo após processamento, utilizando-se um potenciômetro 
digital marca Labmeter model pH 2, aferido com soluções tampão de pH 4 e 7. Obteve-se a acidez total titulável diluindo-se $3 \mathrm{~g}$ de amostra em $40 \mathrm{~mL}$ de água destilada juntamente com quatro gotas de solução de fenolftaleína $1 \% \mathrm{~m} / \mathrm{v}$ seguida de titulação com solução de $\mathrm{NaOH} 1 \mathrm{M}$, expressa em mg de ácido cítrico para cada 100 mL de suco, segundo o Instituto Adolfo Lutz (2008, p. 168). Os sólidos solúveis totais foram determinados por meio da leitura ( ${ }^{\circ}$ Brix) de uma alíquota de suco em um refratômetro portátil da marca Instrutherm modelo RT-30ATC com escala variando de 0 a $30{ }^{\circ}$ Brix. Obteve-se a relação entre SST e ATT mediante o quociente entre as duas análises. As uvas recémcolhidas apresentaram os valores médios de $12,2^{\circ}$ Brix, $\mathrm{pH} 2,82$, quantidade de ácido cítrico $100 \mathrm{~mL}^{-1}$ de suco igual a 0,74 g e 16,48 a relação de SST/ATT.

Submeteram-se os dados obtidos à análise de variância (Teste F) e as médias comparadas pelo teste de Tukey, a 5\% de probabilidade com o software Sisvar (FERREIRA, 2000, p. 256). Para a descrição das variáveis em razão das espessuras de PVC, foram feitas análises de regressão e os modelos que melhor se ajustaram foram selecionados.

\subsection{RESULTADOS E DISCUSSÃO}

De acordo com os resultados expressos no Gráfico 1, referente à análise de perda de massa fresca, nota-se que esta foi influenciada pela espessura da embalagem. Verificou-se perda gradual da massa em todas as unidades experimentais, onde as frutas recobertas com embalagens de PVC apresentaram menores perdas de massa em relação à testemunha (sem cobertura), sendo o aumento na espessura o fator que pode ter contribuído para uma maior estabilidade da massa, já que sua diminuição ocorre principalmente em virtude da perda de água para o meio e o uso de atmosfera modificada diminui a velocidade de perda, pois o filme serve como barreira para a saída de água.

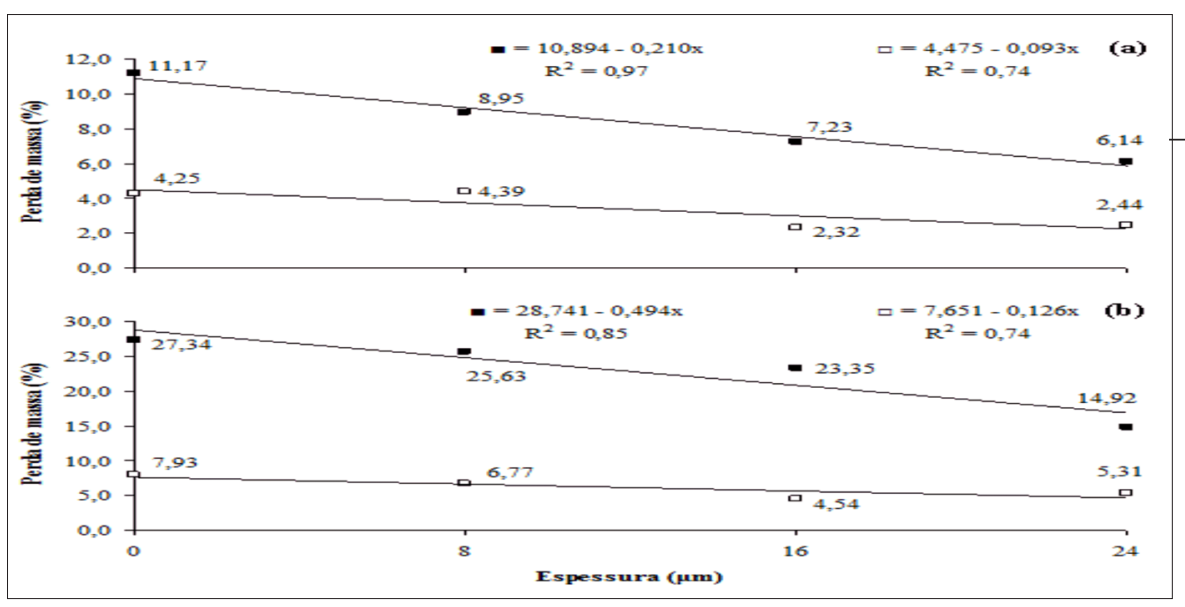

Gráfico 1:

Perda de massa (\%) de uva submetida às temperaturas de $4{ }^{\circ} \mathrm{C}(\square)$ e $25{ }^{\circ} \mathrm{C}(\square)$ em razão das embalagens de diferentes espessuras avaliadas após 6 (a) e 12 dias (b)

Evidência, Joaçaba v. 8 n. 1-2, p. 43-56, janeiro/dezembro 2008 
Características de uvas recobertas com filme plástico de diferentes espessuras...

Resultados semelhantes foram encontrados em estudo realizado por Valentini et al. (2008, p. 1) avaliando os efeitos de diferentes embalagens na conservação pós-colheita de uva Niágara Rosada armazenada sob refrigeração, onde constataram que as embalagens de PVC com $17 \mu \mathrm{m}$ proporcionaram menores porcentagens de perda de massa dos frutos.

As frutas envoltas com filme de PVC mostraram-se com maior potencial de conservabilidade, comprovando, assim, a eficiência do uso de filmes plásticos. Essa informação confirma o relato de Mosca, Mugnol e Vieites (1999, p. 19), no qual é mencionado que a redução da perda de umidade contribui decisivamente na melhor manutenção da qualidade pós-colheita proporcionando desse modo um prolongamento da vida útil das frutas.

A perda de massa também foi influenciada pela época de avaliação e pelo ambiente de armazenamento. Sob temperatura ambiente, as uvas armazenadas durante seis dias sem embalagem apresentaram 1,8 vezes maior perda de massa que naquelas embaladas com PVC de $24 \mu \mathrm{m}$, enquanto que sob refrigeração essas perdas foram 1,7 vezes maiores, evidenciando o efeito da embalagem na redução da perda de massa das frutas. De acordo com Scalon, Dell'olio e Fornasieri (2004, p. 1966) esse resultado sugere que a embalagem associada à refrigeração proporciona menores taxas transpiratórias das uvas ao manter maior umidade relativa no ambiente e menor atividade respiratória; na temperatura de $25^{\circ} \mathrm{C}$, assim como Brackmann, Vizzoto e Ceretta (2002, p. 1026), constatou-se que a aceleração da perda de peso acontece em consequência de uma maior atividade respiratória da uva promovida pelo aumento da atividade metabólica das frutas.

Carvalho e Lima (2002, p. 682) observaram, em sua revisão, que a perda de massa tem efeitos sobre a fisiologia dos tecidos vegetais, podendo antecipar a maturação e a senescência de frutas. Essa perda depende do tempo de armazenamento e da transpiração. A perda de água é a causa principal da deterioração, resultando não somente em perdas quantitativas, mas, na aparência, causando o murchamento e enrugamento na qualidade textural e nutricional. Conforme a Tabela 2, o ambiente refrigerado e a avaliação aos seis dias da instalação do experimento foram as condições de menor perda de massa (3,35\%), enquanto que, no mesmo ambiente, avaliando aos 12 dias, esse valor aumentou para 6,14\% que, segundo Lulu, Castro e Pedro Junior (2005, p. 485) quando a perda de massa é de 4 a $5 \%$, as bagas começam a apresentar enrugamento, fato esse observado no presente experimento.

Nos resultados da análise de SST (Gráfico 2) observa-se que se as frutas embaladas em filme de PVC de $24 \mu \mathrm{m}$ apresentaram maior contenção quanto à evolução dos teores de SST, pressupondose um estádio menos avançado de amadurecimento dessas frutas quando comparados à testemunha, confirmando com os resultados de Sarantóupolos e Soler (1989, p. 112), no qual é ressaltado que por meio da modificação atmosférica das frutas pelo uso de filmes plásticos, pode-se retardar a velocidade do processo de amadurecimento das frutas. 


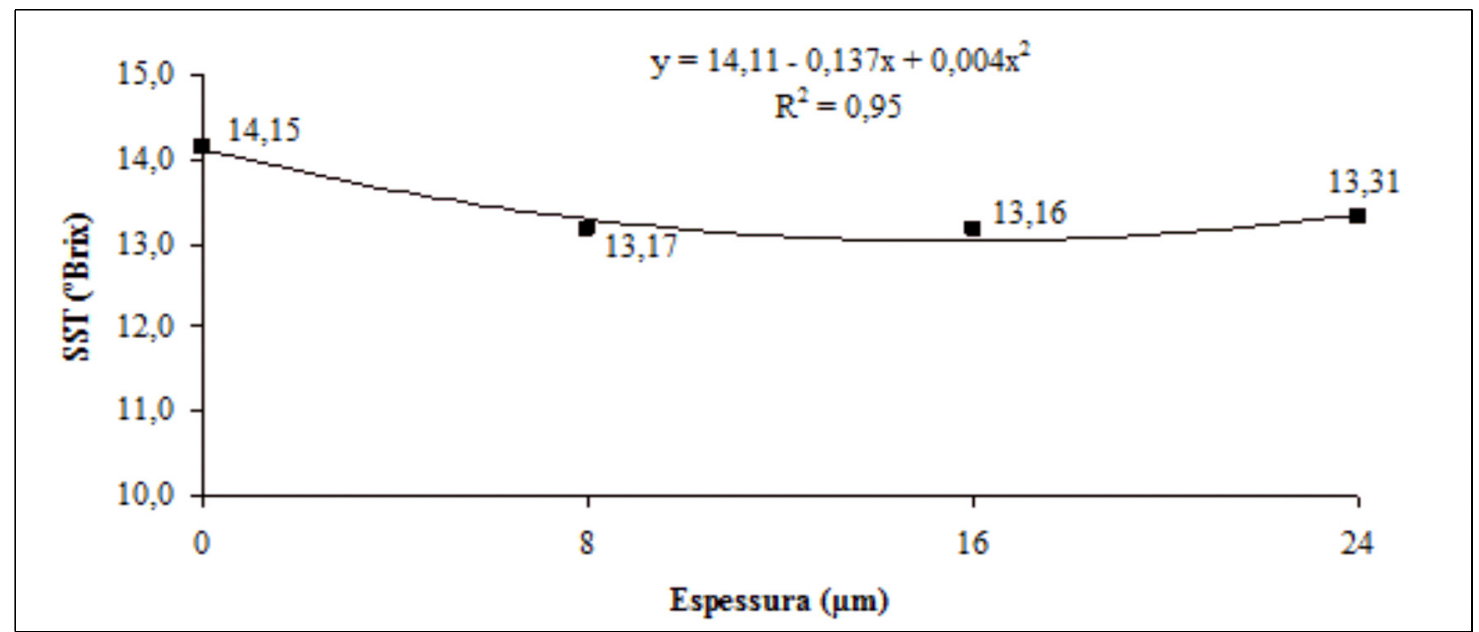

Gráfico 2: o Brix de uva submetida às temperaturas de $4^{\circ} \mathrm{C}$ e $25^{\circ} \mathrm{C}$ em razão das embalagens de diferentes espessuras avaliadas após 6 e 12 dias

Não foi constatada diferença estatística para os fatores época de avaliação e temperatura de armazenamento. Embora Chitarra e Chitarra (2005, p. 275) afirmam que no ponto ideal de colheita da uva a quantidade de SST deve ficar entre 14 a $17^{\circ}$ Brix, a média foi de $13,45^{\circ}$ Brix.

Conforme a Tabela 2, o pH apresentou variação significativa entre temperaturas de armazenamento, com média de 2,80. Sob refrigeração, as uvas apresentaram menor $\mathrm{pH}$, o que pode ser explicado pela menor perda de água observada nessa condição, contribuindo, assim, para concentrar os ácidos orgânicos presentes no suco celular e elevar aparentemente a acidez, uma vez que os ácidos orgânicos tendem a diminuir durante o amadurecimento das frutas, em virtude de sua utilização como substrato respiratório ou de sua conversão em açúcares.

Tabela 2: Características físicas, físico-químicas e químicas de uva embalada com diferentes espessuras de embalagens submetidas a duas temperaturas de armazenamento pós-colheita e avaliadas em duas épocas (continua)

\begin{tabular}{|c|c|c|c|}
\hline Tratamentos & 6 dias & 12 dias & Média \\
\hline \multicolumn{4}{|c|}{ Perda de massa $(\%)$} \\
\hline $4^{\circ} \mathrm{C}$ & B $3,35 \mathrm{~b}$ & A 6,14 b & $4,74 \mathrm{~b}$ \\
\hline $25^{\circ} \mathrm{C}$ & B 8,37 a & A $22,81 \mathrm{a}$ & $15,59 \mathrm{a}$ \\
\hline Média & B 5,86 & A 14,47 & 10,16 \\
\hline \multirow[t]{2}{*}{ CV (\%) } & 24,48 & & \\
\hline & & SST $\left({ }^{\circ}\right.$ Brix $)$ & \\
\hline $4^{\circ} \mathrm{C}$ & B 13,20 a & A 13,83 a & $13,52 \mathrm{a}$ \\
\hline $25^{\circ} \mathrm{C}$ & A 13,40 a & A 13,36 a & $13,38 \mathrm{a}$ \\
\hline Média & A 13,30 & A 13,60 & 13,45 \\
\hline \multirow[t]{2}{*}{ CV (\%) } & 5,16 & & \\
\hline & & pH & \\
\hline $4^{\circ} \mathrm{C}$ & A $2,77 \mathrm{~b}$ & A 2,72 b & $2,74 \mathrm{~b}$ \\
\hline
\end{tabular}

Evidência, Joaçaba v. 8 n. 1-2, p. 43-56, janeiro/dezembro 2008 
Características de uvas recobertas com filme plástico de diferentes espessuras...

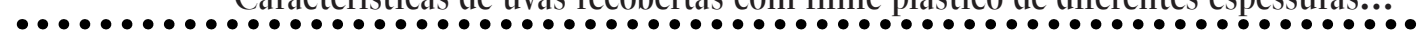

Tabela 2: Características físicas, físico-químicas e químicas de uva embalada com diferentes espessuras de embalagens submetidas a duas temperaturas de armazenamento pós-colheita e avaliadas em duas épocas (conclusão)

\begin{tabular}{cclc}
\hline Tratamentos & $\mathbf{6}$ dias & $\mathbf{1 2}$ dias & Média \\
\hline $\mathbf{2 5}^{\circ} \mathbf{C}$ & A 2,84 a & A 2,89 a & 2,86 a \\
\hline Média & A 2,81 & A 2,80 & 2,80 \\
\hline $\mathbf{C V ~}(\%)$ & 2,44 & &
\end{tabular}

$\operatorname{ATT}\left(\mathrm{g} 100 \mathrm{~mL}^{-1}\right)$

\begin{tabular}{cccc}
$\mathbf{4}^{\circ} \mathbf{C}$ & A 0,67 a & A 0,60 a & 0,64 a \\
$\mathbf{2 5}{ }^{\circ} \mathbf{C}$ & A 0,64 a & B 0,51 a & 0,57 a \\
\hline Média & A 0,65 & B 0,56 & 0,60 \\
\hline $\mathbf{C V ~ ( \% ) ~}$ & 19,26 &
\end{tabular}

SS/ATT

\begin{tabular}{cccc}
$\mathbf{4}^{\circ} \mathbf{C}$ & A 20,23 a & A 23,41 a & 21,82 a \\
$\mathbf{2 5}^{\circ} \mathbf{C}$ & B 21,80 a & A 26,88 a & 24,34 a \\
\hline Média & B 21,02 & A 25,14 & 23,08 \\
\hline CV (\%) & 22,65 & & \\
\hline
\end{tabular}

Nota: Médias seguidas pela mesma letra maiúscula na horizontal e minúscula na vertical, não diferem entre si pelo teste de Tukey $(\mathrm{p}<0,05)$.

Além disso, a manutenção da uniformidade nos frutos embalados individualmente ocorre devido ao uso do filme de PVC associado ao menor contato do fruto com a atmosfera, o que garantiu maior retardamento das transformações bioquímicas responsáveis pela alteração do pH dos frutos.

Para as variáveis ATT e a relação SST/ATT foram constatadas diferenças significativas apenas para o fator época de avaliação. A maior quantidade de ATT dos tratamentos armazenados por seis dias deve estar relacionada com a maior concentração de ácidos orgânicos nas frutas que, com o processo de amadurecimento, diminuíram significativamente e, aos 12 dias chegou a 0,56 g $100 \mathrm{~mL}^{-1}$, valor abaixo da média geral, que foi de $0,60 \mathrm{~g} 100 \mathrm{~mL}^{-1}$.

Gonzalez, Ayub e Werlang (2003, p. 1), em experimento realizado para avaliar o efeito do Ethephon aplicado em pós-colheita e da embalagem de PVC de $14 \mu \mathrm{m}$ em frutos de caqui (Diospyros kaki L.) cv. Fuyu armazenados à temperatura de $25^{\circ} \mathrm{C}$, assim como os nossos resultados, observaram um decréscimo na ATT em razão do tempo, diferindo estatisticamente aos 4 e 8 dias após o tratamento, entretanto, não foram observados efeitos significativos da embalagem de PVC.

A relação SST/ATT aumentou durante o armazenamento devido à diminuição da acidez. Chitarra e Chitarra (2005, p. 275) citam que a relação SST/ATT propicia uma boa avaliação das frutas, sendo mais representativa que a medição isolada de açúcares ou da acidez, e deve ser igual ou superior a 20 no ponto ideal de colheita da uva. Aos 12 dias de armazenamento as uvas atingiram um valor de SST/ATT superior ao da média, que foi de 23,08, o que é desejável para o mercado de frutas (THÉ et al., 2001, p. 362). Já Mattiuz et al. (2009, p. 47), avaliando a qualidade pós-colheita de três cultivares 
de uvas de mesa sem sementes (apirênicas) submetidas ao processamento mínimo e armazenadas sob refrigeração e na temperatura ambiente relataram que a relação SS/AT naquelas armazenadas à temperatura ambiente foi influenciada pelo período de armazenamento, pois o desequilíbrio entre os teores de açúcares e ácidos ao longo deste permite inferir que as frutas apresentaram perda da qualidade organoléptica.

Melo e Lima (2003, p. 1337) avaliaram filmes de PVC com diferentes espessuras na conservação pós-colheita de frutos de nêspera (Eriobotrya japonica) em ambiente refrigerado $\left(3 \pm 2{ }^{\circ} \mathrm{C}\right.$ ) por um período de 50 dias, sendo os filmes com espessuras de 20 e $30 \mu \mathrm{m}$ os mais adequados. Contudo, os autores indicam que o mais viável economicamente seria utilizar o PVC com $20 \mu \mathrm{m}$, pois esse não diferiu estatisticamente do filme de $30 \mu \mathrm{m}$. Entretanto, no que diz respeito à qualidade visual que é diretamente relacionada com a perda de massa, os nossos dados indicam a possibilidade de substituir o filme de $24 \mu \mathrm{m}$ pelo de $16 \mu \mathrm{m}$ somente em caso de dispor de ambiente refrigerado, caso contrário, o filme de PVC com maior espessura seria preferível.

\section{CONCLUSÃO}

Os resultados obtidos com este trabalho permitiram concluir que a utilização de embalagens de PVC reduz a perda de massa de uvas e mantém praticamente inalterado o teor de sólidos solúveis totais; quando associado ao uso de refrigeração a $4{ }^{\circ} \mathrm{C}$ a qualidade das frutas é conservada por até 12 dias.

\section{REFERÊNCIAS}

ABE, Lucile Tiemi et al. Compostos fenólicos e capacidade antioxidante de cultivares de uvas Vitis labrusca L. e Vitis vinifera L. Ciência e Tecnologia de Alimentos, Campinas, v. 27, n. 2, p. 394400, 2007.

ARAÚJO, Paolo Germanno Lima et al. Qualidade físico-química e química de frutos de clones de aceroleira recobertos com filme de PVC e conservados por refrigeração. Semina: Ciências Agrárias, Londrina, v. 30, n. 4, p. 867-880, out./dez. 2009.

BENATO, Eliane Aparecida. Colheita, manuseio e conservação de uvas finas de mesa. Informe Agropecuário, Belo Horizonte, v. 19, n. 194, p. 96-100, 1998.

BRACKMANN, Auri; VIZZOTTO, Márcia; CERETTA, Marcelo. Qualidade de uvas cvs Dona Zilá e tardia de Caxias sob diferentes condições de armazenamento. Ciência e Agrotecnologia, Lavras, v. 26, n. 5, p. 1019-1026, set./out. 2002.

Evidência, Joaçaba v. 8 n. 1-2, p. 43-56, janeiro/dezembro 2008 
Características de uvas recobertas com filme plástico de diferentes espessuras....

CARVALHO, Ana Vânia; LIMA, Luiz Carlos de Oliveira. Qualidade de kiwi minimamente processados e submetidos a tratamentos com ácido ascórbico, ácido cítrico e cloreto de cálcio.

Pesquisa Agropecuária Brasileira, v. 37, n. 5, p. 679-685, 2002.

CARVALHO, Ruy Inácio Neiva; MANICA, Ivo. Influência de estádios de maturação e condições de armazenamento na conservação da acerola (Malpighia glabra L.). Pesquisa Agropecuária Brasileira, Brasília DF, v. 29, n. 5, p. 681-688. 1994.

CHITARRA, Maria Isabel Fernandes; CHITARRA, Adimilson Bosco. Pós-colheita de frutas e hortaliças: fisiologia e manuseio. 2. ed. rev. e ampl. Lavras: UFLA, 2005.

EMPRESA DE PESQUISA AGROPECUÁRIA E EXTENSÃO RURAL. Normas técnicas para o cultivo da videira em Santa Catarina. 2. ed. Florianópolis: Epagri, 2005.

FERRARI, Carlos Kusano Bucalen; TORRES, Elizabeth Aparecida Ferraz da Silva. Biochemical pharmacology of functional foods and prevention of chronic diseases of aging. Biomedicine $\boldsymbol{\&}$ Pharmacotherapy, v. 57, p. 251-260, jul. 2003.

FERREIRA, Daniel Furtado. Análises estatísticas por meio do Sisvar para Windows versão 4.0. In: REUNIÃO ANUAL DA REGIÃO BRASILEIRA DA SOCIEDADE INTERNACIONAL DE BIOMETRIA, 45., 2000, São Carlos. Anais... São Carlos: UFSCar, 2000.

GONZALEZ, Angela Fuentes; AYUB, Ricardo Antônio; WERLANG, Carolina. Utilização de ethephon e embalagem de PVC na maturação de frutos de caqui (Diospyros kaki 1.) cv. Fuyu. Disponível em: < http://www.uepg.br/uepg_departamento/defit/labioveg/paper.html> . Acesso em: 27 maio 2010.

HUNG, Li-Man et al. Cardioprotective effect of resveratrol, a natural antioxidant derivaded from grapes. Cardiovascular Research, n. 47, p. 549-555, 2000.

INSTITUTO ADOLFO LUTZ. Métodos químicos e físicos para análise de alimentos. 4. ed. São Paulo: Instituto Adolfo Lutz, 2008.

INSTITUTO BRASILEIRO DE VINHO. Produção de uvas cai 4\% no Brasil em 2009. In: ABANORTE. Minas Gerais. 2010. Disponível em: < http:/www.abanorte.com.br/noticias/ producao-de-uvas-cai-4-no-brasil-em-2009>. Acesso em: 21 abr. 2010. 
Wanessa Scopel, Julierme Zimmer Barbosa, Daniela Hoffmann

LULU, Jorge; CASTRO, Josalba V.; PEDRO JUNIOR, Mário J. Armazenamento refrigerado da uva de mesa 'Romana' (A1105) cultivada sob cobertura plástica. Engenharia Agrícola, v. 25, n. 2, p. 481-487, 2005.

LULU, Jorge; CASTRO, Josalba Vidigal; PEDRO JÚNIOR, Mário José. Efeito do microclima na qualidade da uva de mesa 'Romana' cultivada sob cobertura plástica. Revista Brasileira de Fruticultura, Jaboticabal, v. 27, n. 3, p. 422-425, dez. 2005.

MATTIUZ, Ben-Hur et al. Efeito da temperatura no armazenamento de uvas apirênicas minimamente processadas. Revista Brasileira de Fruticultura, v. 31, n. 1, p. 44-52, 2009.

MELO, Anderson Adriano Martins; LIMA, Luiz Carlos de Oliveira. Influência de três diferentes embalagens de PVC na vida pós-colheita de nêspera. Ciência e Agrotecnologia, Lavras. v. 27, n. 6, p.1330-1339, 2003.

MELLO, Loiva Maria Ribeiro de. Produção e comercialização de Uvas e Vinhos - Panorama 2005. Disponível em: < http://www.cnpuv.embrapa.br/publica/.../panorama2005-producao.pdf> . Acesso em: 27 maio 2010.

MOSCA, José Luiz; MUGNOL, Marcia Maria; VIEITES, Rogério Lopes. Atmosfera modificada na pós-colheita de frutas e hortaliças. Botucatu: Fepaf, 1999.

PATARO, Lineu Losada; SILVEIRA JÚNIOR, Vivaldo. Relação entre o período de pós-colheita e a vida de prateleira no resfriamento de rúcula. Revista Brasileira de Produtos Agroindustriais, Campina Grande, v. 6, n. 2, p. 157-164, 2004.

PINHEIRO, Érika Sousa et al. Estabilidade físico-química e mineral do suco de uva obtido por extração a vapor. Revista Ciência Agronômica, Fortaleza, v. 40, n. 3, p. 373-380, jul./set. 2009.

SARANTÓUPOLOS, Claire Isabel Grígoli de Luca. Embalagens para vegetais minimamente processados - Fresh cut. Boletim de tecnologia e desenvolvimento de embalagens, n. 5, p. 4, 1997.

SARANTÓUPOLOS, Claire Isabel Grígoli de Luca; SOLER, R. M. Embalagens com atmosfera modificada/controlada. In: SARANTÓUPOLOS, Claire Isabel Grígoli de Luca; SOLER, R. M. Novas tecnologias de acondicionamento de alimentos: embalagens flexíveis e semi-rígidas. Campinas: Ital, 1989.

Evidência, Joaçaba v. 8 n. 1-2, p. 43-56, janeiro/dezembro 2008 
Características de uvas recobertas com filme plástico de diferentes espessuras....

SCALON, Silvana de Paula Quintão; DELL'OLIO, Paolo; FORNASIERI, José Luiz. Temperatura e embalagens na conservação pós-colheita de Eugenia uvalha Cambess - Mirtaceae. Ciência Rural, v. 34, n. 6, nov./dez. 2004.

THÉ, Patrícia Maria Pontes et al. Efeito da temperatura de armazenamento e do estádio de maturação sobre a composição química do abacaxi cv. Smooth Cayenne L. Ciência e Agrotecnologia, v. 25, n. 2, p. 356-363, mar./abr. 2001.

VALENTINI, Sílvia Regina de Toledo et al. Conservação de uva 'Niágara Rosada' em diferentes embalagens e sob refrigeração. In: CONGRESSO BRASILEIRO DE FRUTICULTURA, 20., 2008, Vitória. Anais... Vitória: Sociedade Brasileira de Fruticultura, 2008.

ZAICOVSKI, Cristiane Brauer et al. Resveratrol na qualidade pós-colheita de morangos "Camarosa". Revista Brasileira de Agrociência, v. 12, n. 4, p. 443-446, out./dez. 2006.

YAMASHITA, Fábio et al. Influência de diferentes embalagens de atmosfera modificada sobre a aceitação de uvas finas de mesa var. Itália mantidas sob refrigeração. Ciência e Tecnologia de Alimentos, v. 20, n. 1, p. 110-114, 2000. 
